\title{
Monitoring adolescents and young people with inflammatory bowel disease during transition to adult healthcare
}

\author{
Alenka J Brooks* ${ }^{1}$ Philip J Smith* ${ }^{2}$ James O Lindsay ${ }^{3,4}$
}

\begin{abstract}
${ }^{1}$ Academic Department of Gastroenterology, Sheffield Teaching Hospitals NHS Foundation Trust, Royal Hallamshire Hospital, Sheffield, UK

${ }^{2}$ Centre for Gastroenterology and Hepatology, Royal Free Hospital, London, UK

${ }^{3}$ Bart's Health NHS Trust, The Royal London Hospital, London, UK

${ }^{4}$ Centre for Immunology and Infectious Disease, Blizard Institute, Barts and the London School of Medicine, Queen Mary University of London, London, UK
\end{abstract}

\section{Correspondence to}

Dr James 0 Lindsay, Bart's Health NHS Trust, The Royal London Hospital, London E1 1BB, UK; James.Lindsay@bartshealth. nhs.uk

${ }^{*} \mathrm{AJB}$ and PJS are co-first authors.

Received 28 August 2016 Revised 13 December 2016 Accepted 15 December 2016 Published Online First 10 January 2017

\section{CrossMark}

\section{To cite: Brooks AJ}

Smith PJ, Lindsay JO.

Frontline Gastroenterology 2018;9:37-44.

\begin{abstract}
The transition of adolescents and young people (AYP) with inflammatory bowel disease (IBD) from paediatric to adult healthcare requires coordination between healthcare care providers to achieve optimum outcomes. Transition into adulthood is a time of major challenges physically, developmentally, emotionally and psychosocially for AYP living with IBD. Healthcare professionals must monitor the AYP progress proactively with attention to each of these parameters throughout the transition period to ensure that milestones are attained, and skills for self-management are formed. Thus, achieving the desired goals in both clinical and pastoral areas requires intensive monitoring from a multidisciplinary team across healthcare providers.
\end{abstract}

\section{INTRODUCTION}

Transition of adolescents and young people (AYP) with chronic physical and medical conditions to adult-orientated healthcare systems is a purposeful, planned movement, which requires coordinated action between services and active monitoring of the patient throughout. In contrast, transfer of care is the formal administrative process by which care moves to adult from paediatric care. Transition into adulthood can be a challenging period for all adolescents and involves the development and expression of personal identity and sexuality. For AYP with inflammatory bowel disease (IBD), transition into adulthood can present greater challenges and psychosocial aspects may take priority over their healthcare resulting in anxiety and stress. ${ }^{1}$
Monitoring of AYP with IBD is an essential component of successful transition to ensure that physical milestones, optimal treatment outcomes and personal goals are achieved. Key areas to consider include assessment of disease phenotype, monitoring disease activity to ensure remission, appropriate monitoring of complex therapeutics and attention on the psychosocial aspects of IBD. These areas may interact, for example, poor disease control can result in reduced growth, failure to engage with healthcare, ${ }^{2}$ inadequate transition, non-compliance with medication and increased likelihood of requiring surgery. ${ }^{3-5}$ Successful monitoring of AYP with IBD requires focused and dedicated transition services with the long-term goal of reducing the risk of disease progression, complications and/or adverse psychosocial outcomes.

\section{MONITORING CLINICAL DISEASE IN AYP WITH IBD}

Monitoring of disease activity is crucial to prevent disease progression and reduce the risk of relapse or complications in AYP who characteristically present with an aggressive and extensive disease phenotype.

\section{Disease phenotype}

AYP with IBD present with a more advanced and extensive phenotype at diagnosis resulting in higher rates of surgery than adults, although rates of other disease complications are similar to adults. ${ }^{2}$ Upper gastrointestinal disease is a more common finding in $\mathrm{AYP}^{6}$ which mandates a different approach to investigations at 
diagnosis and therapeutic management. ${ }^{7}$ Differing investigation and management practices can present practical and logistical difficulties in AYP with IBD as they transfer between paediatric and adult care and require monitoring to improve consistency.

\section{Disease progression and approach to treatment}

AYP with IBD are more likely to receive immunosuppressive medications and biological therapy than those diagnosed in adulthood. ${ }^{8}$ Thus, a 'top-down' approach has been advocated for AYP with extensive disease with early combined immunosuppression. ${ }^{9}$ Although not specific to AYP, the REACT (Randomised Evaluation of an Algorithm for Crohn's Treatment) study ${ }^{9}$ demonstrated the benefit of this approach with a reduction in surgery, hospitalisation and other serious disease-related complications as did an earlier study evaluating early combined immunosuppression in newly diagnosed Crohn's disease. ${ }^{10}$ Accelerated introduction of multiple therapies requires attention to monitoring in terms of assessing response to an individual intervention, monitoring of drug leaves and also for adherence to treatments. ${ }^{11}$ Monitoring of disease control can be challenging due to AYP embarrassment and reluctance to report symptoms, which may result in delay in initial diagnosis and progress through the therapeutic algorithm. ${ }^{12}$ In addition, asymptomatic AYP require careful monitoring to exclude occult disease, side effects of medication and to ensure therapeutic levels. ${ }^{711} 13$

\section{Growth and puberty}

There is anthropometric evidence of growth retardation and pubertal delay secondary to the malabsorption and anorexia associated with inflammation, and corticosteroid use in $10 \%-40 \%$ of AYP with IBD. ${ }^{14} 15$ Therapeutic strategies to induce remission are critical to maximise growth potential and velocity and ensure that developmental milestones are obtained within normal timescales, ${ }^{15}$ while addressing concerns over body image. ${ }^{16}$ Corticosteroid use can result in stunted growth and puberty in AYP and is associated with reduced quality of life and an increased psychological distress and depression. ${ }^{17}{ }^{18}$ Healthcare providers in adult and paediatric settings must monitor growth, pubertal development and related psychological morbidity.

\section{MONITORING PSYCHOSOCIAL ISSUES IN AYP WITH IBD}

Successful monitoring of AYP with IBD during transition aims to optimise self-awareness and selfmanagement skills. Ensuring that AYP attain academic achievement and psychosocial development should be a central aim of transition (see figure 1), which can be supported through the use of additional psychological input, online information resources and other technology. ${ }^{19}$

\begin{tabular}{|c|c|}
\hline $\begin{array}{l}\text { Psychological morbidity, } \\
\text { anxiety and depression } \\
\text { Impact on adherence } \\
\text { Impact on attendance } \\
\text { Impact on self } \\
\text { management } \\
\text { Impact on timing of } \\
\text { transition }\end{array}$ & $\begin{array}{l}\text { Non compliance with } \\
\text { steroids } \\
\text { Anxiety regarding need for } \\
\text { surgery/stoma } \\
\text { Non engagement with } \\
\text { stoma care post } \\
\text { operatively }\end{array}$ \\
\hline $\begin{array}{l}\text { Sexuality, relationships, } \\
\text { fertility and peer pressure }\end{array}$ & $\begin{array}{c}\text { Employment issues and } \\
\text { foreign travel }\end{array}$ \\
\hline $\begin{array}{l}\text { Impact on adherence, } \\
\text { attendance and self } \\
\text { management } \\
\text { Risk taking behaviours } \\
\text { affecting health } \\
\text { Concern over future } \\
\text { fertility }\end{array}$ & $\begin{array}{l}\text { Concern over future } \\
\text { employability } \\
\text { - Stress associated with } \\
\text { employment and impact } \\
\text { on health } \\
\text { - Preparing appropriately } \\
\text { for foreign travel }\end{array}$ \\
\hline $\begin{aligned} \text { Impor } \\
\text { explc }\end{aligned}$ & $\begin{array}{l}\text { velopmental priorities to } \\
\text { itor in AYPs in transition }\end{array}$ \\
\hline
\end{tabular}

Figure 1 Important psychosocial and developmental priorities interact and require assessment and monitoring in adolescents and young people (AYP) in transition from paediatric to adult healthcare services.

\section{Psychological morbidity in AYP}

AYP with IBD have been estimated to be at 4.6 -fold increased risk of clinically significant symptoms of anxiety or depression than healthy peers. ${ }^{20} \mathrm{~A}$ recent systematic review has identified multiple risk factors for psychological morbidity including increased disease severity, lower socioeconomic status, corticosteroids, parental stress and older age at diagnosis. ${ }^{21}$ Furthermore, AYP may display regressive behaviour during transition ${ }^{22}$ and feel a sense of abandonment relating to transfer to adult care. ${ }^{23}$ AYP deal with IBD using a variety of coping strategies, commonly employing an 'avoidant coping' strategy where an individual distracts themselves with social diversion, ${ }^{24}$ behaviours associated with disease relapse. $^{25} \mathrm{~A}$ number of studies have demonstrated improvement in adolescents well-being with psychological interventions. ${ }^{26}$ Healthcare professionals should consider the use of validated monitoring tools to aid identification of psychological morbidity, for example, Hospital Anxiety and Depression Scale. ${ }^{27}$

\section{Body image and surgery}

Body image distortion is not uncommon during adolescence and is associated with negative health behaviours. ${ }^{28}$ Major concern has focused around the impact of surgery and especially stoma formation ${ }^{28} 29$ as well as the use of corticosteroids on a patient's body image during the transition period. ${ }^{16} \mathrm{~A}$ body image questionnaire has been specifically developed and validated to assess the psychosocial burden in IBD. ${ }^{28}$ 


\section{Employment issues}

AYP cite concern that their chronic illness will compromise employment opportunities, for example, in chronic cardiorespiratory conditions AYP describe viewing health and occupational future as uncertain. ${ }^{30}$ Patients with IBD are as likely to engage in full-time employment as non-IBD patients into adulthood, ${ }^{31}$ but the anxiety they experience about their prospects in this areas should be addressed.

\section{Expectations of parents and carers}

Ongoing parental/carer involvement during transition and subsequent transfer is to be expected by healthcare professionals (HCPs) due to the gradual acquisition of AYP independence. ${ }^{32}$ Parents/carers report a sense of anxiety regarding joining a new healthcare team and a feeling of inadequately informed. ${ }^{33}$ In other chronic diseases, age, gender or severity of disease does not predict level of concern regarding transition in AYP and their parents/carers. ${ }^{34}$ HCPs should ensure monitoring of parental/carer information requirements during the transition of the AYP.

\section{Sexuality, relationships and health risk behaviours}

Addressing sexual relationships and health risk behaviours are cited as important to AYP, but they remain reluctant to ask for information and can feel inhibited by the presence of parents/guardians. ${ }^{4}{ }^{35}$ Lifestyle factors such as the impact of medication on foreign travel, the risks of tattoos and piercings and also peer pressure related to health risk behaviours have been highlighted by AYP as unmet area in transition care. ${ }^{4}$ The use of generic tools for evaluation of health risk behaviours in AYP with IBD such as Home, Education/employment, peer group Activities, Drugs, Sexuality, and Suicide/depression (HEADSS) inventory is recommended as a useful tool for monitoring this activity. $^{36}$

\section{Fertility and immunosuppression}

Concerns regarding future fertility are described by AYP with $\mathrm{IBD},{ }^{37}$ with research in AYP with other inflammatory disorders expressing concern over disclosure of chronic illness to potential partners. ${ }^{38} 39$ AYP have concerns regarding the impact of immunosuppression on fertility and future children's health. ${ }^{40}$ Online patient information resources are available to support AYP with questions regarding fertility and immunosuppression. ${ }^{41}$

\section{Foreign travel}

Concern related to travelling and going on foreign holidays relates to the risk of relapse during travel, risk of incontinence, traveller's diarrhoea and the requirement for vaccination while on immunosuppressive therapies. ${ }^{42}{ }^{43}$ Although not specific to the AYP, this group is more likely to plan extensive travel therefore preemptive supporting and monitoring is recommended to ensure that AYP aspirations are achieved through the use of online resources such as http://www.ibdpassport.com. ${ }^{44}$

\section{MONITORING IBD-SPECIFIC KNOWLEDGE AND SELF-MANAGEMENT SKILLS IN AYP WITH IBD}

Disease-specific knowledge and self-management skills have been identified as key components predicting successful transition in an individual. ${ }^{45}$ The ongoing cognitive development of AYP with IBD is an important consideration during transition and monitoring the following aspects of AYP disease-specific knowledge and self-management skills enable successful transition.

\section{Disease and medication knowledge}

AYP are successful at recalling IBD medications, but are less able to recall dosages and adverse effects of their medications, which does improve with age ${ }^{46}$ but not disease duration. ${ }^{47}$ Most AYP are able to name their disease and describe it to a friend. ${ }^{48}$ Monitoring of disease and medication knowledge across healthcare providers is vital to enabling successful selfmanagement skills in adulthood.

\section{Medication adherence}

AYP report a number of barriers to oral medication adherence including lack of time, forgetting, being away from home and interference with an activity. ${ }^{49}$ Reasons for AYP discontinuing medications include side effects, feeling well and believing that the medications are not working. The use of monotherapy and less frequent dose administration are both associated with fewer barriers to adherence. ${ }^{50}$ Medication nonadherence which can be monitored using the Morisky Medication Adherence Scale (MMAS-8), ${ }^{51}$ may be a manifestation of anxiety and/or depressive symptoms. ${ }^{21}$ Consideration of monitoring of psychological morbidity in AYP with medication non-adherence is recommended.

\section{Healthcare system knowledge and skills}

AYP entering the adult healthcare system may not be prepared or knowledgeable about the differences between paediatric and adult care. ${ }^{32}$ The majority of AYP rely on their parents/carers to manage the logistics of arranging clinic appointments and medication pick-up, but most do assume responsibility for doing most of the talking during the clinic visit. ${ }^{48}$ Communication with medical teams does not appear to improve with age. ${ }^{47}$

\section{MONITORING INTERVENTIONS THAT BUILD INDEPENDENCE IN AYP WITH IBD}

Strategies to promote independence and development of self-management skills in AYP during paediatricadult transition include a number of IBD-specific and 
generic educational and self-efficacy resources, which can be used to develop and monitor skill acquisition.

\section{The MyHealth passport}

A customised, wallet-sized card providing patients, families and caregivers with a comprehensive summary of medical information. HCPs complete the passport with AYP deciding what information should be included. AYP completing MyHealth Passport have been demonstrated to have variable disease knowledge weaknesses and an organised transition programme could monitor such weaknesses and include agespecific educational components to address deficits in AYP knowledge. ${ }^{52}$

\section{IBD-specific educational programmes}

Theory-based IBD educational programme for AYP aims to improve IBD-specific knowledge, using a free web-based interactive multimedia CD-ROM. The programme includes key areas regarding IBD symptoms, diagnosis, complications, medications, nutrition, social functioning and personal testimonials. AYP have demonstrated improved knowledge scores, as measured by Crohn's and Colitis Knowledge questionnaire, immediately after the intervention and up to 9 months afterwards. ${ }^{53}$

\section{IBD-specific self-efficacy assessment tool}

This has been developed for AYP and families and includes a number of domains such as general independence, IBD-specific knowledge, skills/knowledge for independent transition clinic visits/process, coping with IBD and readiness for transfer to the adult gastroenterologist. Parents frequently overestimate AYP self-efficacy relative to how the AYP score themselves. Male gender, higher education level and length of time since first transition clinic were positive predictors of self-efficacy. ${ }^{54}$

\section{Generic transition intervention}

$\mathrm{MD} 2 \mathrm{Me}$ is a generic educational resource that has been evaluated in a number of chronic diseases including IBD. This intervention uses technology-based communication between the healthcare team and AYP (web-based and text message-based intervention) to enhance access to the healthcare team and to provide disease management and skill-based interventions. In a randomised controlled trial, this has been shown to improve health-related self-efficacy, performance of disease management tasks and patient-initiated communications. However, no beneficial impact was demonstrated for quality-of-life measure, functional performance or for disease status. ${ }^{19}$

\section{MONITORING AYP TRANSITION READINESS}

The timing of transition requires an assessment of the AYP's maturity and readiness for transfer of care necessitating flexibility in transition pathways. Several factors determine an individual AYP's readiness for transition, and these should be monitored. Clinician's perception of transition-related readiness correlates poorly with AYP interactive/functional health literacy measures, with only $16 \%$ of AYP with IBD thought to have adequate transition readiness. ${ }^{55}$ The use of tools to monitor transition readiness may be of great value to both AYP and their carers/families. Most focus on AYP knowledge of disease and related transition skills with other potentially important factors such as psychometric data infrequently collected. Importantly, data demonstrating the ability of such tools to predict outcomes of transition are lacking. ${ }^{33}$

\section{Developmental checklists}

NASPGHAN has developed age and developmentally appropriate checklists for paediatric HCPs. The transition model suggested commencing at the age of 12 , to allow ample opportunity to anticipate and practice the new roles for the AYP and their carers/families. ${ }^{56}$

\section{IBD transition protocol}

This provides a timeline underpinned by age-related developmental milestones to aid HCPs monitor AYP with regard to the self-management and self-efficacy skills required for transition. The authors of this tool recognise the variable rate observed in maturity and developmental milestones seen in all AYP and suggest it be tailored to the individual. ${ }^{57}$

\section{Generic transition readiness tool}

A number of generic tools exist including the Transition Readiness Assessment Questionnaire which has been found to have a high internal consistency and validity. ${ }^{58} 59$ The University of North Carolina TR(x)ANSITION Scale is a tool for assessing the effectiveness of a transition process. ${ }^{60}$ It uses a semistructured interview with the patient alongside the use of medical records and has a high inter-rater reliability.

\section{MONITORING HEALTHCARE OUTCOMES AND DEVELOPING HEALTHCARE PROVISION}

Inherent differences between healthcare models present challenges and opportunities for the care of AYP with IBD. AYP move from a paediatric system which is focused on the family unit with a multidisciplinary approach, in contrast to an adult system which is focused on an individual. Importantly, a sense of attachment to paediatric HCPs is likely to have developed, with AYP reporting a sense of abandonment or be uncertain regarding transfer to adult care. ${ }^{23}$

\section{Outcomes of transition programmes}

Few trials have evaluated the cost-effectiveness of appropriate transition in IBD or other chronic diseases. A recent UK study has shown that establishment of a transition programme in IBD resulted in 
improvements in drug compliance, clinical attendance and growth with a reduced need for surgical intervention compared with those with no formalised transition arrangement before transfer. ${ }^{5}$ A further French retrospective study has evaluated the transition process at least 1 year into adult care and found that those with more severe IBD were more likely to transition to a University hospital and to attend the joint transition visit, with nearly all of those attending reporting that the joint visit building confidence in the new adult system. ${ }^{61}$ TRANSIT, a UK-based study assessed the impact of structured transition on outcomes relevant to AYP and their respective healthcare team. AYP with IBD undergoing structured transition

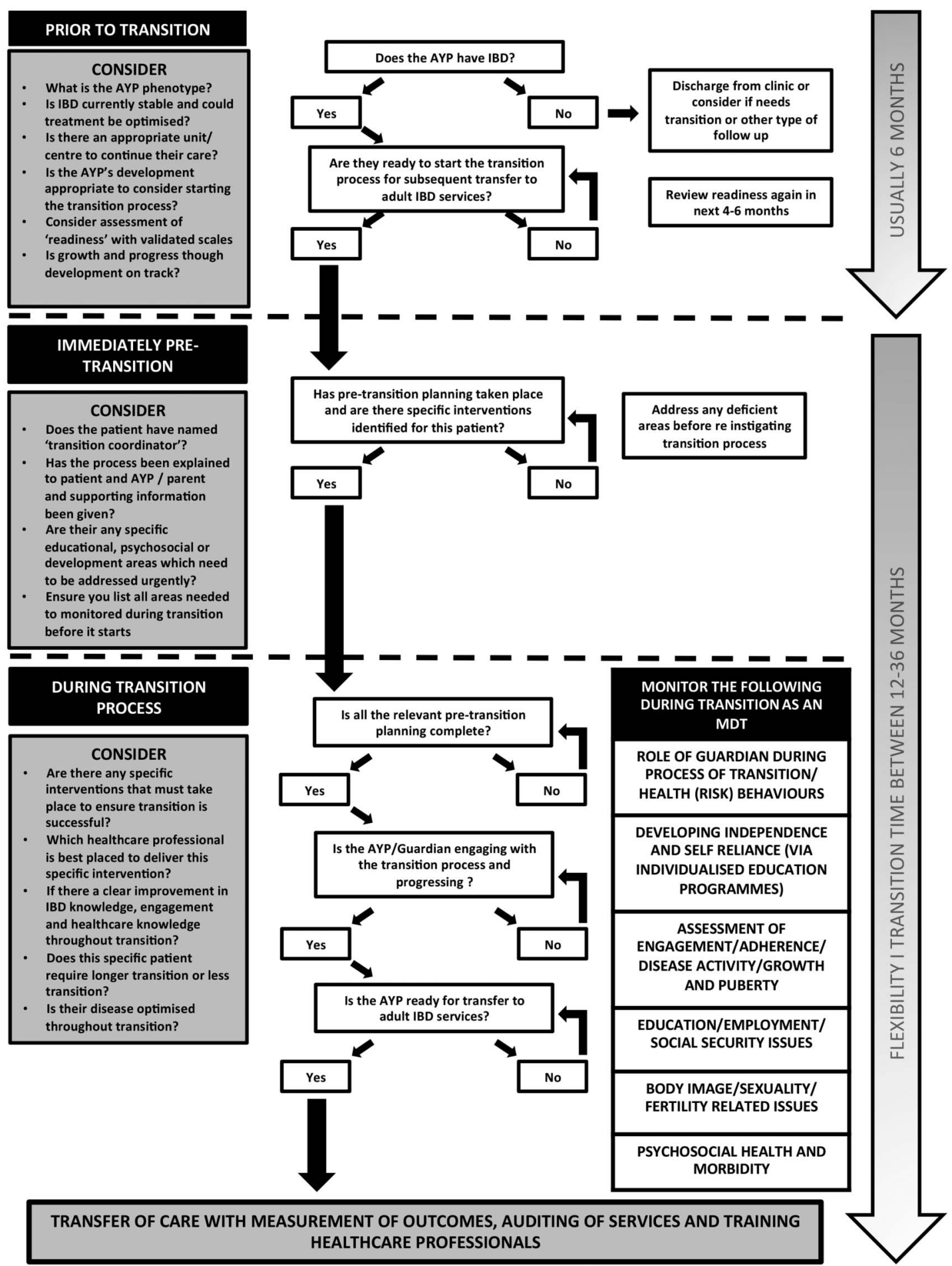

Figure 2 A summary of the different stages of adolescents and young people (AYP) with inflammatory bowel disease (IBD) transition that highlights elements that must be monitored during this process from the perspective of paediatric to adult healthcare services. 
experienced a reduction in IBD flares, were more likely to remain in steroid-free remission and were less likely to have an emergency admission during the first 12-months postindex compared with patients not receiving structured transition care. ${ }^{62}$

\section{Provision and training of staff}

Integration of a dedicated nurse transition coordinator frequently a specialist nurse, often, but not exclusively based within the paediatric service is a crucial part of the transition service. ${ }^{63}{ }^{64}$ The ever increasingly vital role that the IBD specialist nurse has in transition care has not been formally evaluated, but in adult studies IBD specialist nurses increase access to and availability of IBD services and enhance patient education. ${ }^{65}$ Despite their pivotal role, $76 \%$ of IBD nurse specialists do not feel they are adequately prepared to participate in transition of long-term conditions. ${ }^{66}$ Likewise, adult healthcare providers cite suboptimal training in adolescent medicine as a barrier to participating in a transition programme. ${ }^{67} 68$

\section{Monitoring and developing IBD services}

Audit, research recommendations as outlined in the recent National Institute for Health and Care Excellence guidance ${ }^{69}$ and quality improvement programmes are vital to the development of word-class IBD transition services for AYP, as is the development of technology within transition services and monitoring its effectiveness (see figure 2).

\section{CONCLUSION}

Monitoring of AYP during transition is complex and multifaceted. It requires HCPs to provide coordinated healthcare focusing on disease-related goals while simultaneously assessing the psychosocial needs of their patients. This requires a pragmatic but sensitive approach to monitoring, where AYP are empowered to lead areas of self-monitoring. Monitoring tools and interventions are recommended for use in assessing transition readiness and to promote AYP independence, in conjunction with monitoring of healthcare outcomes and promoting audit, service development and research in this under investigated field.

Correction notice This article has been corrected since it published Online First. Figure 2 has been updated.

Twitter Follow Alenka Brooks@alenkabrooks and Philip Smith @DrPhilipJSmith

Competing interests None declared.

Provenance and peer review Not commissioned; externally peer reviewed.

\section{REFERENCES}

1 Tierney S, Deaton C, Jones A, et al. Liminality and transfer to adult services: a qualitative investigation involving young people with cystic fibrosis. Int J Nurs Stud 2013;50:738-46.
2 Van Limbergen J, Russell RK, Drummond HE, et al. Definition of phenotypic characteristics of childhood-onset inflammatory bowel disease. Gastroenterology 2008;135:1114-22.

3 Calsbeek H, Rijken M, Dekker J, et al. Disease characteristics as determinants of the labour market position of adolescents and young adults with chronic digestive disorders. Eur J Gastroenterol Hepatol 2006;18:203-9.

4 Tuchman LK, Slap GB, Britto MT. Transition to adult care: experiences and expectations of adolescents with a chronic illness. Child Care Health Dev 2008;34:557-63.

5 Cole R, Ashok D, Razack A, et al. Evaluation of outcomes in adolescent inflammatory bowel disease patients following transfer from pediatric to adult health care services: case for transition. J Adolesc Health 2015;57:212-17.

6 Aloi M, Lionetti P, Barabino A, et al. Phenotype and disease course of early-onset pediatric inflammatory bowel disease. Inflamm Bowel Dis 2014;20:597-605.

7 Ruemmele FM, Veres G, Kolho KL, et al. Consensus guidelines of ECCO/ESPGHAN on the medical management of pediatric Crohn's disease. J Crohns Colitis 2014;8:1179-207.

8 Van Assche G, Dignass A, Reinisch W, et al. The second European evidence-based Consensus on the diagnosis and management of Crohn's disease: Special situations. J Crohn's Colitis 2010;4:63-101.

9 Khanna R, Bressler B, Levesque BG, et al. Early combined immunosuppression for the management of Crohn's disease (REACT): a cluster randomised controlled trial. Lancet 2015;386:1825-34.

10 D'Haens G, Baert F, van Assche G, et al. Early combined immunosuppression or conventional management in patients with newly diagnosed Crohn's disease: an open randomised trial. Lancet 2008;371:660-7.

11 Kamperidis N, Goodhand JR, Chowdhury FA, et al. Factors associated with nonadherence to thiopurines in adolescent and adult patients with inflammatory bowel disease. J Pediatr Gastroenterol Nutr 2012;54:685-9.

12 Sawczenko A, Sandhu BK. Presenting features of inflammatory bowel disease in Great Britain and Ireland. Arch Dis Child 2003;88:995-1000.

13 Goodhand JR, Kamperidis N, Sirwan B, et al. Factors associated with thiopurine non-adherence in patients with inflammatory bowel disease. Aliment Pharmacol Ther 2013;38:1097-108.

14 Shamir R. Nutritional aspects in inflammatory bowel disease. J Pediatr Gastroenterol Nutr 2009;48(Suppl 2):S86-8.

15 Heuschkel R, Salvestrini C, Beattie RM, et al. Guidelines for the management of growth failure in childhood inflammatory bowel disease. Inflamm Bowel Dis 2008;14:839-49.

16 Muller KR, Prosser R, Bampton P, et al. Female gender and surgery impair relationships, body image, and sexuality in inflammatory bowel disease: patient perceptions. Inflamm Bowel Dis 2010;16:657-63.

17 Szigethy E, Craig AE, Iobst EA, et al. Profile of depression in adolescents with inflammatory bowel disease: implications for treatment. Inflamm Bowel Dis 2009;15:69-74.

18 Szigethy E, Levy-warren A, Whitton S, et al. Depressive symptoms and inflammatory bowel disease in children and adolescents: a cross-sectional study. J Pediatr Gastroenterol Nutr 2004;39:395-403.

19 Huang JS, Terrones L, Tompane T, et al. Preparing adolescents with chronic disease for transition to adult care: a technology program. Pediatrics 2014;133:e1639-46. 
20 Mackner LM, Crandall WV. Brief report: psychosocial adjustment in adolescents with inflammatory bowel disease. J Pediatr Psychol 2006;31:281-5.

21 Brooks AJ, Rowse G, Ryder A, et al. Systematic review: psychological morbidity in young people with inflammatory bowel disease-risk factors and impacts. Aliment Pharmacol Ther 2016;44:3-15.

22 Adamiak T, Walkiewicz-Jedrzejczak D, Fish D, et al. Incidence, clinical characteristics, and natural history of pediatric IBD in Wisconsin: a population-based epidemiological study. Inflamm Bowel Dis 2013;19:1218-23.

23 de Silva PSA, Fishman LN. Transition of the patient with IBD from pediatric to adult care-an assessment of current evidence. Inflamm Bowel Dis 2014;20:1458-64.

24 van der Zaag-Loonen HJ, Grootenhuis MA, Last BF, et al. Coping strategies and quality of life of adolescents with inflammatory bowel disease. Qual Life Res 2004;13:1011-19.

25 Bitton A, Dobkin PL, Edwardes MD, et al. Predicting relapse in Crohn's disease: a biopsychosocial model. Gut 2008;57:1386-92.

26 Szigethy E, Bujoreanu SI, Youk AO, et al. Randomized efficacy trial of two psychotherapies for depression in youth with inflammatory bowel disease. J Am Acad Child Adolesc Psychiatry 2014;53:726-35.

27 Zigmond AS, Snaith RP. The hospital anxiety and depression scale. Acta Psychiatr Scand 1983;67:361-70.

28 McDermott E, Mullen G, Moloney J, et al. Body image dissatisfaction: clinical features, and psychosocial disability in inflammatory bowel disease. Inflamm Bowel Dis 2015;21:353-60.

29 Moser G, Tillinger W, Sachs G, et al. Disease-related worries and concerns: a study on out-patients with inflammatory bowel disease. Eur J Gastroenterol Hepatol 1995;7:853-8.

30 Moola FJ, Norman ME. "Down the rabbit hole": enhancing the transition process for youth with cystic fibrosis and congenital heart disease by re-imagining the future and time. Child Care Health Dev 2011;37:841-51.

31 Netjes JE, Rijken M. Labor participation among patients with inflammatory bowel disease. Inflamm Bowel Dis 2013;19:81-91.

32 Leung Y, Heyman MB, Mahadevan U. Transitioning the adolescent inflammatory bowel disease patient: guidelines for the adult and pediatric gastroenterologist. Inflamm Bowel Dis 2011;17:2169-73.

33 Schwartz LA, Daniel LC, Brumley LD, et al. Measures of readiness to transition to adult health care for youth with chronic physical health conditions: a systematic review and recommendations for measurement testing and development. J Pediatr Psychol 2014;39:588-601.

34 Boyle MP, Farukhi Z, Nosky ML. Strategies for improving transition to adult cystic fibrosis care, based on patient and parent views. Pediatr Pulmonol 2001;32:428-36.

35 Stabile L, Rosser L, Porterfield KM, et al. Transfer versus transition: success in pediatric transplantation brings the welcome challenge of transition. Progr Transpl 2005;15:363-70.

36 Goldenring JM, Rosen DS. Getting into adolescent heads: an essential update. Contemp Pediatr 2004;21:64-90.

37 van der Woude CJ, Kolacek S, Dotan I, et al. European evidenced-based consensus on reproduction in inflammatory bowel disease. J Crohns Colitis 2010;4:493-510.
38 Shaw KL, Southwood TR, McDonagh JE. User perspectives of transitional care for adolescents with juvenile idiopathic arthritis. Rheumatol 2004;43:770-8.

39 McDonagh JE. Young people first, juvenile idiopathic arthritis second: transitional care in rheumatology. Arthritis Rheum 2008;59:1162-70.

40 Aujoulat I, Janssen M, Libion F, et al. Internalizing motivation to self-care: a multifaceted challenge for young liver transplant recipients. Qual Heal Res 2014;24:357-65.

41 Fertility and IBD. Edition 5a. 2016. http://www. crohnsandcolitis.org.uk

42 Soonawala D, van Eggermond AM, Fidder H, et al. Pretravel preparation and travel-related morbidity in patients with inflammatory bowel disease. Inflamm Bowel Dis 2012;18:2079-85.

43 Rahier JF, Magro F, Abreu C, et al. Second European evidence-based consensus on the prevention, diagnosis and management of opportunistic infections in inflammatory bowel disease. J Crohns Colitis 2014;8:443-68.

44 Welcome to IBD Passport|IBD Passport. http://www. ibdpassport.com/

45 Paine CW, Stollon NB, Lucas MS, et al. Barriers and facilitators to successful transition from pediatric to adult inflammatory bowel disease care from the perspectives of providers. Inflamm Bowel Dis 2014;20:2083-91.

46 Fishman LN, Houtman D, van Groningen J, et al. Medication knowledge: an initial step in self-management for youth with inflammatory bowel disease. J Pediatr Gastroenterol Nutr 2011;53:641-5.

47 Whitfield EP, Fredericks EM, Eder SJ, et al. Transition readiness in pediatric patients with inflammatory bowel disease: patient survey of self-management skills. J Pediatr Gastroenterol Nutr 2015;60:36-41.

48 Fishman LN, Barendse RM, Hait E, et al. Self-management of older adolescents with inflammatory bowel disease: a pilot study of behavior and knowledge as prelude to transition. Clin Paediatr 2010;49:1129-33.

49 Ingerski LM, Baldassano RN, Denson LA, et al. Barriers to oral medication adherence for adolescents with inflammatory bowel disease. J Pediatr Psychol 2010;35:683-91.

50 Greenley RN, Stephens M, Doughty A, et al. Barriers to adherence among adolescents with inflammatory bowel disease. Inflamm Bowel Dis 2010;16:36-41.

51 Morisky DE, Ang A, Krousel-Wood M, et al. Predictive validity of a medication adherence measure in an outpatient setting. J Clin Hypertens (Greenwich) 2008;10:348-54.

52 Benchimol EI, Walters TD, Kaufman M, et al. Assessment of knowledge in adolescents with inflammatory bowel disease using a novel transition tool. Inflamm Bowel Dis 2011;17:1131-7.

53 Boamah LM, Bohren JR, Pentiuk S, et al. Development and testing of a CD-ROM program for improving adolescent knowledge of inflammatory bowel disease. J Pediatr Gastroenterol Nutr 2010;50:521-5.

54 Zijlstra M, De Bie C, Breij L, et al. Self-efficacy in adolescents with inflammatory bowel disease: a pilot study of the "IBD-yourself", a disease-specific questionnaire. J Crohns Colitis 2013;7:e375-85.

55 Huang JS, Tobin A, Tompane T. Clinicians poorly assess health literacy-related readiness for transition to adult care in adolescents with inflammatory bowel disease. Clin Gastroenterol Hepatol 2012;10:626-32. 
56 Checklist_PatientandHealthcareProdiver_TransitionfromPedtoAdult. pdf (cited 26 May 2016). http://www.naspghan.org/files/ documents/pdfs/medical-resources/ibd/Checklist PatientandHealthcareProdiver_TransitionfromPedtoAdult.pdf

57 Hait E, Arnold JH, Fishman LN. Educate, communicate, anticipate-practical recommendations for transitioning adolescents with IBD to adult health care. Inflamm Bowel Dis 2006;12:70-3.

58 Sawicki GS, Lukens-Bull K, Yin X, et al. Measuring the transition readiness of youth with special healthcare needs: validation of the TRAQ-Transition Readiness Assessment Questionnaire. J Pediatr Psychol 2011;36:160-71.

59 Wood DL, Sawicki GS, Miller MD, et al. The Transition Readiness Assessment Questionnaire (TRAQ): its factor structure, reliability, and validity. Acad Pediatr 2014;14:415-22.

60 Ferris ME, Harward DH, Bickford K, et al. A clinical tool to measure the components of health-care transition from pediatric care to adult care: the UNC TR(x)ANSITION scale. Ren Fail 2012;34:744-53.

61 Dabadie A, Troadec F, Heresbach D, et al. Transition of patients with inflammatory bowel disease from pediatric to adult care. Gastroentérologie Clin Biol 2008;32:451-9.

62 McCartney S, Lindsay JO, Russell RK, et al. A structured paediatric to adult transition service in patients with inflammatory bowel disease reduces disease flares, requirement for steroids and emergency admissions: the TRANSIT study. United Eur Gastroenterol J 2016;2(Suppl 1).

63 Rapley P, Davidson PM. Enough of the problem: a review of time for health care transition solutions for young adults with a chronic illness. J Clin Nurs 2010;19: 313-23.

64 Pywell A. "Transition: moving on well"- from paediatric to adult health care. Br J Nurs 2010;19:652-6.

65 Younge L, Norton C. Contribution of specialist nurses in managing patients with IBD. Br J Nurs 2007;16:208-12.

66 Houston Y, Lindsay JO, Jenkins H, et al. Perspectives of transition care in inflammatory bowel disease: a survey. Gastrointest Nurs 2012;10:2-6.

67 Hait EJ, Barendse RM, Arnold JH, et al. Transition of adolescents with inflammatory bowel disease from pediatric to adult care: a survey of adult gastroenterologists. J Pediatr Gastroenterol Nutr 2009;48:61-5.

68 Sebastian S, Jenkins H, McCartney S, et al. The requirements and barriers to successful transition of adolescents with inflammatory bowel disease: differing perceptions from a survey of adult and paediatric gastroenterologists. J Crohns Colitis 2012;6:830-44.

69 Transition from children's to adults' services for young people using health or social care services. National Institute for Health and Care Excellence NICE guideline [NG43]. 2016. https://www.nice.org.uk/guidance/ng43 